\title{
MOLECULAR DETECTION OF AMINOGLYCOSIDE-MODIFYING ENZYME GENES IN ACINETOBACTER BAUMANNII CLINICAL ISOLATES
}

\author{
Mohsen Heidary ${ }^{1}$, Alireza Salimi Chirani ${ }^{2}$, SAeEd KhOShNOOd ${ }^{3}$,

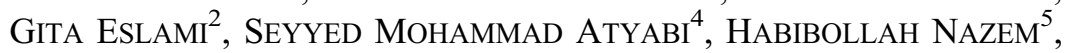 \\ MOHAMMAD FAZILATI $^{5}$, ALI HASHEMI ${ }^{2}$ and SALEH SOLEIMANI ${ }^{5 *}$ \\ ${ }^{1}$ Department of Microbiology, School of Medicine, Iran University of Medical Sciences, \\ Tehran, Iran \\ ${ }^{2}$ Department of Microbiology, School of Medicine, Shahid Beheshti University of \\ Medical Sciences, Tehran, Iran \\ ${ }^{3}$ Department of Microbiology, School of Medicine, Ahvaz Jundishapur University of \\ Medical Sciences, Ahvaz, Iran \\ ${ }^{4}$ Department of Pilot Nanobiotechnology, Pasteur Institute of Iran, Tehran, Iran \\ ${ }^{5}$ Department of Biology, Payame Noor University, Isfahan, Iran
}

(Received: 2 July 2016; revised manuscript received: 25 July 2016; accepted: 19 October 2016)

Acinetobacter baumannii is a major opportunistic pathogen in healthcare settings worldwide. In Iran, there are only few reports on the prevalence of aminoglycoside resistance genes among $A$. baumannii isolates. The aim of this study was to investigate the existence of aminoglycoside-modifying enzyme (AME) genes from $A$. baumannii strains collected at a university teaching hospital in Iran. One hundred $A$. baumannii strains were collected between 2014 and 2015 from hospitalized patients at Loghman Hakim Hospital, Tehran, Iran. Antimicrobial susceptibility was determined by disk diffusion method according to the Clinical and Laboratory Standards Institute recommendations. The DNA was extracted using a kit obtained from Bioneer Co. (Korea) and was used as a template for polymerase chain reaction. The most active antimicrobial agent against these strains was colistin. The rate of extended-spectrum cephalosporin resistance was $97 \%$. The $a a d A 1, a a d B, a a c\left(6^{\prime}\right)-I b$, and $a a c(3)-I I a$ genes were found in $85 \%, 77 \%, 72 \%$, and $68 \%$ of $A$. baumannii isolates, respectively. This study showed a high prevalence rate of AME genes in A. baumannii. This prevalence rate has explained that further aminoglycoside resistance genes may have role in the resistance of clinical isolates of A. baumannii. Therefore, control and treatment of serious infections caused by this opportunistic pathogen should be given more consideration.

\footnotetext{
*Corresponding author; E-mail: soleimanibiosci@gmail.com
} 
Keywords: Acinetobacter baumannii, aminoglycoside, Iran,
acetyltransferases, adenyltransferases

\section{Introduction}

Acinetobacter baumannii is a major opportunistic, non-fermenting, Gramnegative pathogen in healthcare settings worldwide, and it is now being isolated at an increasing rate from wound infections [1]. The organism's ability to spread among hospitalized patients and to persist for long periods along with multidrug resistance are the major driving forces behind the frequent large outbreaks in different countries [2]. Three decades ago, A. baumannii infections were treated with traditional antibiotics, but during the past two decades, $A$. baumannii resistant to a wide range of antibiotics including aminoglycosides, fluoroquinolones, broadspectrum $\beta$-lactams, and carbapenems has emerged [3]. They can cause a variety of nosocomial infections including pneumonia, meningitis, endocarditis, urinary tract infections, and wound infections especially in hospitalized patients in the intensive care units (ICUs). As infections with drug-resistant $A$. baumannii in patients remain difficult to treat, it is becoming a worldwide threat. Aminoglycosides have long been used for the treatment of $A$. baumannii infections and still are an important alternative for therapy. However, resistance to aminoglycosides has increased in recent years in these bacteria [4-6]. Aminoglycoside-modifying enzymes (AMEs) are the most important mechanism of providing aminoglycoside resistance in A. baumannii clinical strains. Recent studies have shown several resistance mechanisms to aminoglycosides in A. baumannii including enzymatic inactivation by acetyltransferases (AACs) and adenyltransferases (AADs), usually found on transposons and plasmids, which facilitate acquisition of resistance [7-11]. In Iran, to the best of our knowledge, there are only few reports on the prevalence rate of AME genes among clinical strains. The aim of this study was to evaluate the antimicrobial susceptibility of $A$. baumannii strains and to investigate the existence of AME genes from the strains collected at the university teaching hospital in Iran.

\section{Materials and Methods}

\section{Bacterial isolates}

A total of 100 A. baumannii strains were collected between January 2014 and May 2015 from hospitalized patients at Loghman Hakim Hospital, Tehran, Iran. The isolates obtained were tested by conventional, well-recognized biochemical tests including oxidase, motility, and citrate tests as well as their capability to grow 
at $42-44{ }^{\circ} \mathrm{C}$ [12]. Polymerase chain reaction (PCR) was performed based on the method of Hujer et al. [13] for identifying the A. baumannii species.

\section{Antimicrobial susceptibility testing}

Antimicrobial susceptibility was determined by the Kirby-Bauer disk diffusion method (Mast Group, Merseyside, UK) according to the Clinical and Laboratory Standards Institute recommendations [14]. Antimicrobial agents tested were ciprofloxacin (CIP, $30 \mu \mathrm{g}$ ), imipenem (IPM, $10 \mu \mathrm{g}$ ), gentamicin (GEN, $10 \mu \mathrm{g})$, amikacin (AK, $30 \mu \mathrm{g})$, tetracycline (TET, $10 \mu \mathrm{g})$, colistin (CO, $10 \mu \mathrm{g})$, cefepime (CPM, $30 \mu \mathrm{g})$, ceftriaxone (CRO, $30 \mu \mathrm{g})$, ceftazidime (CAZ, $30 \mu \mathrm{g})$, and meropenem (MRP, $10 \mu \mathrm{g})$.

\section{DNA extraction, PCR amplification, and DNA sequencing}

DNA was extracted using a kit obtained from Bioneer Co. (Korea) and was used as a template for PCR. Amplification was achieved under the following thermal cycling conditions: $5 \mathrm{~min}$ at $94^{\circ} \mathrm{C}$ for the initial denaturation followed by 36 cycles of amplification consisting of $45 \mathrm{~s}$ at $94{ }^{\circ} \mathrm{C}, 45 \mathrm{~s}$ at $52-58^{\circ} \mathrm{C}$, and $45 \mathrm{~s}$ at $72{ }^{\circ} \mathrm{C}$, with 5 $\min$ at $72{ }^{\circ} \mathrm{C}$ for the final extension. Target genes, temperatures of annealing, amplicons size, and primers used for PCR amplification are shown in Table I. Results of the PCR were compared with positive controls. The PCR products were analyzed by electrophoresis in a $1 \%-1.5 \% \mathrm{vw}^{-1}$ agarose gel. One of the PCR products was purified, and direct sequencing was done. The PCR amplification was performed for AME genes including $a a d A 1, a a d B$, aac(3)-IIa, and $a a c\left(6^{\prime}\right)-I b$.

\section{Statistical analysis}

This was a descriptive application research study. Statistical analyses were done by MINITAB16 software. The $P$ value and confidence intervals were $\leq 0.05$ and $95 \%$, respectively.

\section{Results}

A. baumannii strains were isolated from 100 hospitalized patients. The patients included $75(75 \%)$ men and $25(25 \%)$ women. The age range of the study population was 5-80 years [mean age $42.5( \pm 10)$ years]. The patterns of antibiotic resistance found in $A$. baumannii isolates showed that resistance to tested 

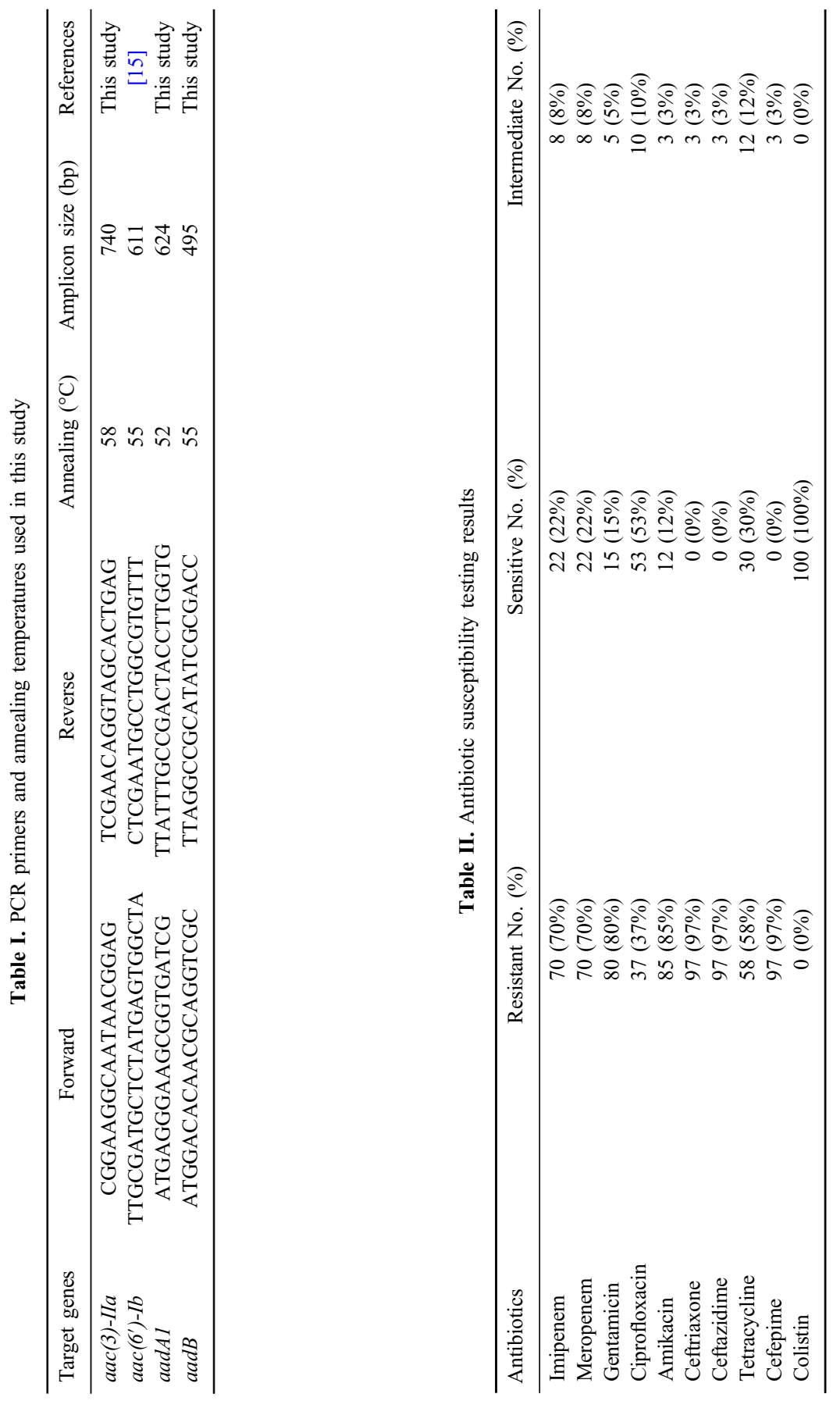
antibiotics was $70(70 \%)$ to IPM, $70(70 \%)$ to MRP, $80(80 \%)$ to GEN, 37 (37\%) to CIP, 85 (85\%) to AK, $97(97 \%)$ to CRO, 58 (58\%) to TET, 97 (97\%) to CPM, 97 (97\%) to CAZ, and 0 (0\%) to CO (Table II). The most active antimicrobial agent against these strains was $\mathrm{CO}$ with $100 \%$ susceptibility. More than $80 \%$ of the isolates resistant against AK and GEN harbored AME genes. The prevalence rate of AAC genes including $a a c\left(6^{\prime}\right)-I b$ and $a a c(3)-I I a$ was $72 \%$ and $68 \%$, and the prevalence rate of AAD genes including aadAl and aadB was reported to be $85 \%$ and $77 \%$, respectively. Sequencing of PCR products for $\mathrm{AAC}$ and $\mathrm{AAD}$ genes was confirmed by BLAST in NCBI.

\section{Discussion}

A. baumannii has emerged as an etiologic threat for diverse nosocomial infections. The organism's ability to spread among hospitalized patients and to persist for long periods along with multidrug resistance are the major driving forces behind the frequent large outbreaks in different countries [16-18]. The increase of $A$. baumannii strains during recent years, along with rapid progress of antibacterial resistance, led to this study [1, 19]. Therefore, control, prevention, and treatment of serious infections caused by this bacteria should be considered, and there is a need for revising the treatment protocols to decrease the spread of resistant genes among the clinical isolates. The $a a d A 1, a a d B, a a c\left(6^{\prime}\right)-I b$, and $a a c$ (3)-IIa genes were found in 85 (85\%), 77 (77\%), (72) 72\%, and (68) 68\% of A. baumannii isolates, respectively. In 2006, a US-based study showed the prevalence rates of $a a d A 1$ and $a a d B$ genes were $39 \%$ and $48 \%$, respectively, for multidrug-resistant $A$. baumannii strains [13]. In 2014, a study from Iran showed aadAl and $a a d B$ genes in $27.9 \%$ and $18.6 \%$ of $A$. baumannii strains, respectively [4]. Most of the aminoglycoside resistance in A. baumannii isolates involves the production of AMEs. Previous studies have shown that genes encoding these enzymes can be present on plasmids, transposons, or within integron-type structures. The increase in the prevalence rate of aminoglycosideencoding genes during past decades emphasizes the probable importance of these structures in the distribution of aminoglycoside resistance in A. baumannii isolates as nosocomial pathogens. In a study from the USA, among 313 Enterobacteriaceae, $a a c\left(6^{\prime}\right)-I b$ was present in $50.5 \%$ of isolates [20]. The $a a c\left(6^{\prime}\right)-I b-c r$ gene encrypts an aminoglycoside $\mathrm{AAC}\left(6^{\prime}\right)-\mathrm{Ib}$ variant marked by Trp102Arg and Asp179Tyr substitutions [15, 21]. These changes afford the new enzyme with the ability to acetylate fluoroquinolones harboring an unsubstituted piperazinyl group, such as CIP and norfloxacin [22]. Therefore, this gene confers the reduction of susceptibility to some fluoroquinolones in addition to tobramycin, kanamycin, and 
AK. The results of this study indicated an increase in the prevalence rate of A. baumannii strains isolated from a university teaching hospital in Iran. The detection of different resistance genes in this study confirmed a wide distribution of these genes among A. baumannii strains. The prevalence rate of drug-resistant $A$. baumannii strains in hospitalized patients implies that care should be taken while identifying these isolates, preventing their infections, and selecting for a correct drug treatment against associated infections. The continuous evaluations on the decrease or increase of antibiotic resistance among drug-resistant $A$. baumannii strains could provide the physicians with new therapeutic choices, so that treatment with ineffectual drugs would be stopped and replaced by effectual antibiotics. This fact leads to a diminish in the circulation of drug-resistant $A$. baumannii isolates among ICU patients. Resistance among A. baumannii isolates is continuously increasing, so the best decision on the control of nosocomial infections caused by A. baumannii isolates is the use of antibiogram tests in each geographic area.

\section{Conflict of Interest}

None.

\section{References}

1. Asadollahi, P., Akbari, M., Soroush, S., Taherikalani, M., Asadollahi, K., Sayehmiri, K., Maleki, A., Maleki, M. H., Karimi, P., Emaneini, M.: Antimicrobial resistance patterns and their encoding genes among Acinetobacter baumannii strains isolated from burned patients. Burns 38, 1198-1203 (2012).

2. Hojabri, Z., Pajand, O., Bonura, C., Aleo, A., Giammanco, A., Mammina, C.: Molecular epidemiology of Acinetobacter baumannii in Iran: Endemic and epidemic spread of multiresistant isolates. J Antimicrob Chemother 69, 2383-2387 (2014).

3. Yin, X.-L., Hou, T.-W., Xu, S.-B., Ma, C.-Q., Yao, Z.-Y., Li, W., Wei, L.: Detection of drug resistance-associated genes of multidrug-resistant Acinetobacter baumannii. Microb Drug Resist 14, 145-150 (2008).

4. Aliakbarzade, K., Farajnia, S., Nik, A. K., Zarei, F., Tanomand, A.: Prevalence of aminoglycoside resistance genes in Acinetobacter baumannii isolates. Jundishapur $\mathrm{J}$ Microbiol 7, 1-6 (2014).

5. Jin, W., Wachino, J.-I., Kimura, K., Yamada, K., Arakawa, Y.: New plasmidmediated aminoglycoside $6^{\prime}-\mathrm{N}$-acetyltransferase, AAC(6')-Ian, and ESBL, TLA-3, from a Serratia marcescens clinical isolate. J Antimicrob Chemother 70, 1331-1337 (2015).

6. Wen, J., Zhou, Y., Yang, L., Xu, Y.: Multidrug-resistant genes of aminoglycosidemodifying enzymes and 16S rRNA methylases in Acinetobacter baumannii strains. Genet Mol Res 13, 3842-3829 (2014). 
7. Hakemi-Vala, M., Makhmor, M., Kobarfar, F., Kamalinejad, M., Heidary, M., Khoshnood, S.: Investigation of antimicrobial effect of Tribulus terrestris L. against some gram positive and negative bacteria and candida spp. Novelty Biomed 2, 85-90 (2014).

8. Heidary, M., Bahramian, A., Goudarzi, H., Eslami, G., Hashemi, A., Khoshnood, S.: To study the association between AcrAB and Qep A efflux pumps and ciprofloxacin resistance among Escherichia coli and Klebsiella pneumoniae clinical strains. J Arak Univ Med Sci 19, 1-10 (2016).

9. Goudarzi, H., Hashemi, A., Fatemeh, F., Noori, M., Erfanimanesh, S., Yosefi, N., Heidary, M., Khoshnood, S., Houri, H. R.: Detection of blaDIM, blaAIM, blaGIM, blaNDM and blaVIM Genes among Acinetobacter baumannii strains isolated from hospitalized patients in Tehran hospitals, Iran. Iranian J Med Microbiol 9, 32-39 (2016).

10. Heidary, M., Hashemi, A., Goudarzi, H., Khoshnood, S., Roshani, M., Azimi, H., Goudarzi, M.: The antibacterial activity of Iranian plants extracts against metallo betalactamase producing Pseudomonas aeruginosa strains. J Paramedical Sci 7, 13-19 (2016).

11. Rodríguez-Martínez, J. M., Cano, M. E., Velasco, C., Martínez-Martínez, L., Pascual, Á.: Plasmid-mediated quinolone resistance: An update. J Infect Chemother 17, 149-182 (2011).

12. Huang, L., Sun, L., Yan, Y.: Time to positivity of blood culture is predictive for nosocomial infection and infectious endocarditis instead of other clinical characteristics and prognosis in Acinetobacter baumannii bloodstream infection. J Infect 68, 198-200 (2014).

13. Hujer, K. M., Hujer, A. M., Hulten, E. A., Bajaksouzian, S., Adams, J. M., Donskey, C. J., Ecker, D. J., Massire, C., Eshoo, M. W., Sampath, R., Thomson, J. M., Rather, P. N., Craft, D. W., Fishbain, J. T., Ewell, A. J., Jacobs, M. R., Paterson, D. L., Bonomo, R. A.: Analysis of antibiotic resistance genes in multidrug-resistant Acinetobacter sp. isolates from military and civilian patients treated at the Walter Reed Army Medical Center. Antimicrob Agents Chemother 50, 4114-4123 (2006).

14. Clinical and Laboratory Standards Institute (CLSI). Performance Standards for Antimicrobial Susceptibility Testing; Seventeenth Informational Supplement. CLSI, 2012.

15. Heidary, M., Goudarzi, H., Hashemi, A., Eslami, G., Goudarzi, M., Salimi Chirani, A., Amraei, S.: The prevalence of genes that encode Quinolone resistance in Klebsiella pneumoniae strains isolated from hospitalized patients during 2013-2014. Arch Pediatr Infect Dis, e38343 (2016).

16. Liu, Y., Yang, Y., Zhao, F., Fan, X., Zhong, W., Qiao, D., Cao, Y.: Multi-drug resistant gram-negative enteric bacteria isolated from flies at Chengdu Airport, China. Southeast Asian J Trop Med Public Health 44, 988-996 (2013).

17. Hasani, A., Sheikhalizadeh, V., Ahangarzadeh Rezaee, M., Rahmati-Yamchi, M., Hasani, A., Ghotaslou, R., Goli, H. R.: Frequency of aminoglycoside-modifying enzymes and ArmA among different sequence groups of Acinetobacter baumannii in Iran. Microb Drug Resist 22, 347-353 (2016).

18. Mirnejad, R., Mostofi, S., Masjedian, F.: Antibiotic resistance and carriage class 1 and 2 integrons in clinical isolates of Acinetobacter baumannii from Tehran, Iran. Asian Pac J Trop Biomed 3, 140-145 (2013).

19. Sengupta, S., Kumar, P., Ciraj, A., Shivananda, P.: Acinetobacter baumannii - An emerging nosocomial pathogen in the burns unit Manipal, India. Burns 27, 140-144 (2001).

20. Park, C. H., Robicsek, A., Jacoby, G. A., Sahm, D., Hooper, D. C.: Prevalence in the United States of $a a c\left(6^{\prime}\right)-I b-c r$ encoding a ciprofloxacin-modifying enzyme. Antimicrob Agents Chemother 50, 3953-3955 (2006). 
21. Chiem, K., Jani, S., Fuentes, B., Lin, D. L., Rasche, M. E., Tolmasky, M. E.: Identification of an inhibitor of the aminoglycoside $6^{\prime}$-N-acetyltransferase type $\mathrm{Ib}$ [AAC(6')-Ib] by glide molecular docking. Med Chem Commun 7, 184-189 (2016).

22. Campos, J., Mourão, J., Marçal, S., Machado, J., Novais, C., Peixe, L., Antunes, P.: Clinical Salmonella typhimurium ST34 with metal tolerance genes and an IncHI2 plasmid carrying oqxAB-aac(6')-Ib-cr from Europe. J Antimicrob Chemother 71, 843-845 (2015). 